Article

\title{
Corporate Social Responsibility: Understanding the Mining Stakeholder with a Case Study
}

\author{
Sisi Que ${ }^{1} \mathbb{D}$, Liang Wang ${ }^{2, *}$, Kwame Awuah-Offei ${ }^{3}{ }^{-0}$, Wei Yang ${ }^{1}$ and Hui Jiang ${ }^{1}$ \\ 1 Key Laboratory of Hydraulic and Waterway Engineering of the Ministry of Education, \\ College of River and Ocean Engineering, Chongqing Jiaotong University, Chongqing 400074, China; \\ sq3g3@mst.edu (S.Q.); cquyw@163.com (W.Y.); jianghui1368@163.com (H.J.) \\ 2 State Key Lab of Coal Mine Disaster Dynamics and Control, Chongqing University, Chongqing 404000, China \\ 3 Department of Mining \& Nuclear Engineering, Missouri University of Science \& Technology, Rolla, \\ MO 65409, USA; kwamea@mst.edu \\ * Correspondence: 1w38c@cqu.edu.cn; Tel.: +86-23-6510-5093
}

Received: 21 March 2019; Accepted: 18 April 2019; Published: 23 April 2019

check for updates

\begin{abstract}
The social responsibility of corporate mining has been challenged by a significant socio-political risk from local communities. These issues reduce shareholder value by increasing costs and decreasing the market perception of corporate social responsibility. Community engagement is the process of understanding the behavior and interests of a group of targeted mining communities through surveys and data analysis, with the purpose of incorporating mining community acceptance into the mining sustainability. While mining organizations have discussed community engagement to varying degrees, there are three main shortcomings in current studies, as concluded in the authors' previous research. This paper presents a framework to apply discrete choice theory to improve mining community engagement and corporate mining social responsibility. In addition, this paper establishes the main technical challenges to implement the developed framework, and presents methods to overcome the challenges for future research with a case study. The contribution of this research will transform mine sustainability in a fundamental way by facilitating the incorporation of effective community engagement. This will lead to more sustainable mines that local communities support.
\end{abstract}

Keywords: corporate social responsibility; mining sustainability; mining stakeholder; community engagement

\section{Introduction}

Sustainability in mining implies communities' acceptance of the exploration of a new developing mine and a mine in production. Low levels of community acceptance for mining projects pose significant risks to project success, investors' economic returns, and governance. A lack of acceptance within local communities is the cause of political and social unrest, which leads to security and public relations concerns for mining companies. These issues reduce shareholder value by increasing costs and decreasing the market perception of corporate social responsibility. The Grasberg Mine located in the Irian Jaya Province on the island of New Guinea, Indonesia, which is owned by Freeport-McMoran Copper \& Gold, Inc. (FMI), is a good illustration [1]. Some of the local Papuans question the legitimacy of the Indonesian government's rights to mineral resources, with the population split in their support base, primarily, between those who see economic benefits and those who focus on the environment and perceived social injustice.

A Social License to Operate (SLO) appears to be a way to better manage the social and environmental responsibility of the sector, and thus protect the reputation and legality of mining operations [2]. SLO is a response to the growing demand for the transparency and accountability of activities and 
ensures greater community contribution to projects that affect them. In the era of CSR, a social license acts as a form of strategic risk management for most large companies, minimizing it by making strategic forms of community involvement [3]. The Social License to Operate (SLO) is currently a well-established narrative in the mining sector as a significant element of the CSR's credibility. Mining companies generally use the concept of an SLO as a means of controlling the process, treating SLO as a communication tool for mining entrepreneurs, to inform interested communities about their plans [4-6]. Community engagement is the process of understanding the behavior and interests of a group of targeted mining communities, who have the potential to influence an organization, project, or policy direction, through surveys and data analysis [7-9]. The results are used to manage mining communities by understanding and satisfying their preferences and facilitating the decision-making processes. Community analysis is also helpful for policy makers or managers to better understand the local community as a basis for formulating better policies or management strategies.

However, mining companies, government agencies, and other stakeholders have no systematic way of incorporating mining community acceptance into the design of new mining projects. There are three main shortcomings in current studies, which are outlined in the authors' previous comprehensive literature review: (1) the engagement of community is more likely to reduce to triple bottom; (2) the demographics of local communities are insufficient for the purpose of sustainability; (3) a qualitative method of analysis is predominant [10].

In this study, the authors develop a framework to apply discrete choice theory to understand mining community engagement and improve the shortcomings of existing studies. Nobel prize winner McFadden developed the discrete choice theory [11], which has been applied in the world of market research. This theory analyzes an individual decision marker's preference in discrete choices. Discrete choice theory has been successfully used in econometrics and other disciplines to understand behavior in choice situations [12-15]. IBM used discrete choice theory to study the demand for laptop computers and reconfigure their product line to target various country-specific market segments. AT\&T wireless used this modeling framework to assess demand for proposed wireless communication services [16]. Further, this theory has been employed to study the communities' attitude on renewable energy projects [13]. In the investigation on people's acceptance of hazardous materials transportation [14], discrete choice theory is also used.

Discrete choice theory will enhance the communication of the community and mining company by improving the understanding of community and making the information more accurate. Discrete choice modelling allows a mining company to examine the effect of each mining project attribute (or characteristic) on individual and community preferences. Compared to traditional community engagement methods, a mining company will have a quantitative tool for planning, designing, and managing a mining project. This study will transform mining science and mining engineering practice by using discrete choice theory to obtain the interrelation of preference of the community and the sustainability objectives of a mining operation.

\section{The Framework for Mining Community Engagement}

The primary goal of the developed framework is to understand the local mining community with a quantitative analysis method. Discrete choice theory is used to understand the relationship between community acceptance and mining project sustainability. The demographic diversity of the local community and mining affecting factors beyond environmental, economics, and society will be considered in the quantitative framework.

As a statistical analysis method, discrete choice theory aims at analyzing individual decision marker's preferences. Discrete choice models (DCMs) can help us understand what kind of mining project individuals in a community prefer by comparing different hypothetical options. By identifying patterns in these choices, DCMs will provide insight into how different individuals respond to different mining options. DCMs will allow mining companies to examine the significance of different mining impacts (including social, economic, and environmental and other aspects) of a project on the 
preferences of different groups (demographic diversity) of in the local communities. Compared to traditional stakeholder analysis methods, the mining company will have a quantitative tool for planning, designing, operating, and managing the mining project to facilitate better community engagement.

The developed framework for mining community engagement is shown in Figure 1, including three main parts. First of all, a validated list of key mining attributes and demographic factors need to be identified. Beyond the triple bottom line, the mining attributes also need to consider how the other minor mining impacts will affect community perceptions of mining projects (e.g., governance aspect). Second, the discrete choice experiment (DCE) needs to be designed with the factor list, followed by DCE validation and conduct in a local mining community. Third, different DCMs need to be compared to identify candidate DCMs that are most appropriate for modeling mining community acceptance, and the results of candidate DCMs need to be evaluated to find the most appropriate DCM for mining community acceptance.

In this developed framework, the minor mining attributes and demographic factors could be included in the consideration of mining sustainability and remedy the first and second shortcomings of current studies. In addition, the estimated parameters of mining attributes and demographic factors could explain how these factors affect the local community perception of mining project quantitatively and improve the third shortcomings of existing predominant qualitative analysis methods. This work provides a framework that will help to incorporate community acceptance considerations in mine planning, design, permitting, operation, and closure.

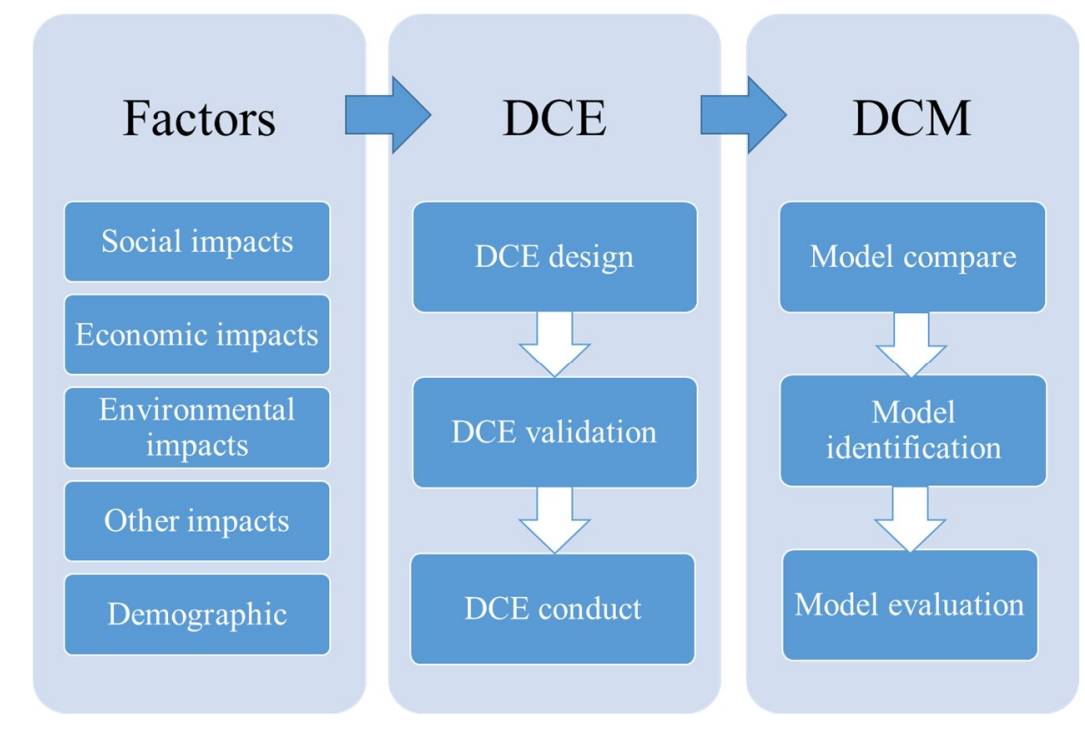

Figure 1. The developed research framework for mining community engagement [17]. DCE, discrete choice experiment; DCM, discrete choice models.

\section{Challenges and Methods in the Developed Framework}

The developed framework needs to overcome three technical challenges to apply discrete choice theory to community acceptance of mining projects: (1) How to identify and verify the important factors (the mining project impacts and demographic factors) that may affect local community acceptance of a mining project; (2) How to design, validate and conduct effective discrete choice experiments that balance cost (number of respondents needed) and cognitive burden (whether the cognitive effort required to make the choices are reasonable); and (3) How to select the most appropriate DCM to describe the local community's acceptance of mining projects. The methods proposed to overcome these three main technical challenges are discussed in the following sections. 


\subsection{How to Identify and Verify the Important Factors}

The first challenge can affect the success of the whole discrete choice experiment and model. The factors considered need to be sufficiently comprehensive; the key issues that various respondents may consider as important should be covered. They also should be intelligible enough to prove that the feedback is valid. Ivanova et al. [18] and Ivanova and Rolfe [19] selected five and seven mining project factors, respectively. Work needs to be down to identify the more important mining project factors from others. Meanwhile, these models' reliability should be investigated before it can be used in community analysis employing DCMs. Pursuant to this challenge, three further issues need to be dealt with: (1) how to distinguish the key mining factors when applying a discrete choice theory; (2) how to find the key demographic factors, which are significant vis-à-vis people's perception of the importance of the mining project attribute; and (3) how to make the list clear and relevant.

A three-step flowchart shown in Figure 2 can be used to identify important mining project factors and key demographic attributes. Step 1 begins with a review of the literature on sustainable development and its relationship to community engagement and then uses the literature to determine the dominant factors (version 1) that affect community perceptions of mining projects. In Step 2, community survey should be used to capture respondents' perception of the level of importance of the identified factors in their decision to support a mining project. Statistical analysis needs to be used to analyze the survey data and determine valid mining impacts and demographic factors (version 2 ). In Step 3, discrete choice experiments need to be designed, involving all important mining project factors. A focus group study should be conducted to evaluate its intelligibility. Based on feedback from the focus group study, the list for clarity, effectiveness and validity were revised (version 3 ).

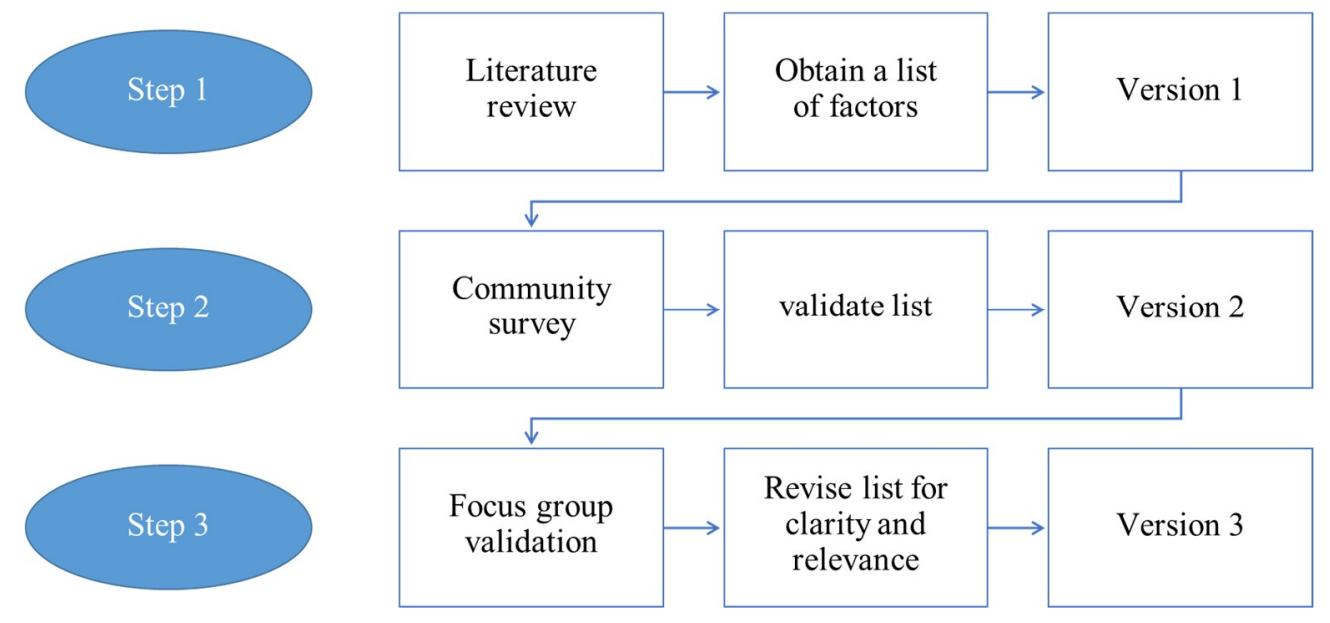

Figure 2. Attributes identification steps [20].

\subsection{How to Design Good Discrete Choice Experiments (DCEs) and Conduct Survey}

According to previous research, surveyed respondents drawn from mining communities consider at least more than 10 mining attribute in their decision to support a mining project [21]. However, the average number considered in a majority of choice experiments was around five or six [22]. Ivanova and Rolfe [19] considered only five characteristics of the mine development options in order to keep it "simple and concise", so that respondents can complete the survey with ease (i.e., a reasonable cognitive burden). Indeed, using only five attributes led to a high alternate specific constant, which indicates that the selected attributes do not fully explain the respondent's preferences [23]. A large number of factors will create difficulties in decision making. Respondents, therefore, need to put in a greater amount of cognitive effort $[24,25]$. A difference between respondents' cognitive abilities and the cognitive burden when they are asked to make the decision will be more obvious. Using more than 10 attributes 
in a discrete choice experiment will, most likely, lead to a higher than bearable cognitive burden for respondents.

The second challenge of incorporating discrete choice theory into mining community analysis is to include sufficient factors in an experiment with a reasonable cognitive burden, which will improve in providing valid results. The DCE design, validation, and conduction processes are shown in Figure 3. There are three hurdles that cannot be ignored: (1) How to design effective discrete choice experiments with more than 10 mining attributes; (2) How to validate the discrete choice experiment design; and (3) How to conduct survey and collect useful data.

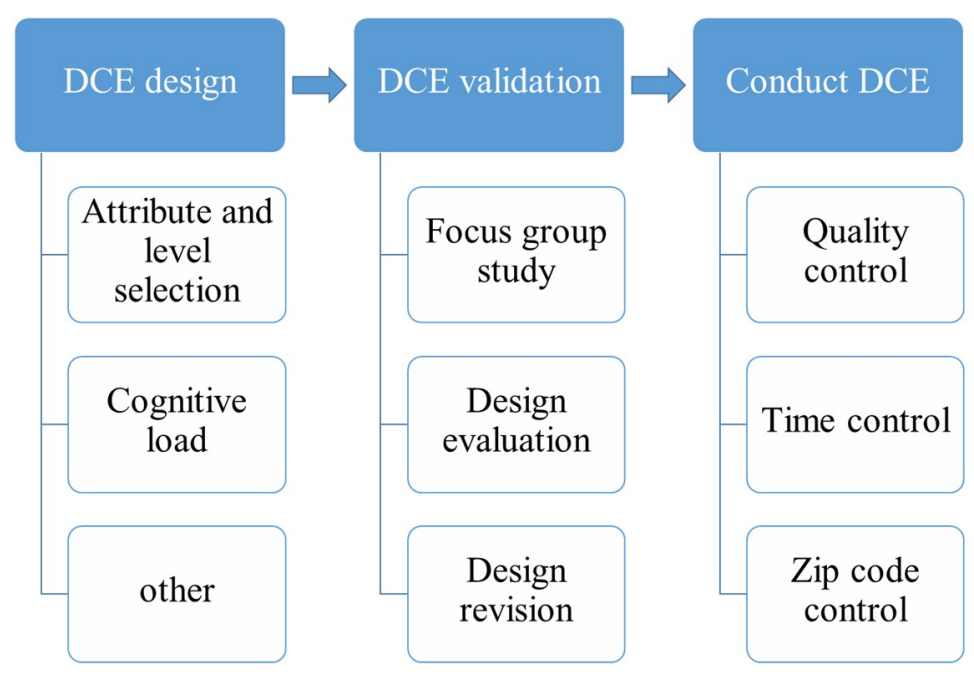

Figure 3. DCE design, validation and conduction processes [26].

The DCE design includes attribute and level selection, cognitive load, and seven other design considerations and steps (i.e., stated preference vs. revealed preference, fractional factorial design, with or without interaction, experimental size, candidate design construction, efficient experiment design, duplicate check, and labeling) [26]. To address DCE validation, a focus group study is needed to capture respondents' perception of the difficulty, clarity, reliability, and validity of the DCE. Statistical analysis should be used to evaluate the level of difficulty and clarity from the focus group results. Also, some revisions need to be done according to the answers of open-ended question. To conduct DCE and collect efficient data for the following DCM, the DCE needs to be conducted with quality control, time control, and zip code control. Quality control questions and minimum complete time should be set in the survey. The purpose of zip code control is to confirm the participants as part of a true local mining community by tracking their zip codes.

\subsection{How to Find the Best DCM for Mining Community Engagement}

The final challenge is how to select the most appropriate DCM to reflect the preference of the community on a mining project. This task involves: (1) conducting a comprehensive literature review of DCMs to identify candidate DCMs that are most appropriate for modeling mining community acceptance; and (2) evaluating the candidate DCMs to select the most suitable DCM for mining community acceptance.

The comprehensive literature review of DCMs was done in Que [17], in which candidate models were also identified. Those candidate models are the conditional logit (CL), conditional logit stratified by questions (CLQ), and mixed logit (ML) models. The CL model is the most widely accepted DCM. This model has been applied to investigate the local communities' preference towards various options in mineral exploration [18,19]. The CLQ model is a special instance of the CL model with a stratified conditional logistic regression to compare the options in each choice set. Compared to the CL model, the stratified analysis in the CLQ model makes it possible to compare the options in each choice set of 
the DCE. In the CL model, the fitting algorithm can only analyze the local communities' preference by comparing all possible combinations at the same time. However, in the real DCE, participants were answering questions one by one, and each question has limited options. The stratified analysis instructs the algorithm to consider the data by choice set, which makes it more practically applicable. As discussed, this option better represents the way respondents consider the choices.

However, both of the CL and CLQ models have two restrictions: fixed taste coefficients $\beta_{n}$ and the iia property (independence irrelevant alternatives) [17]. Compared with the CL and CLQ models, the mixed logit model is not constrained by these two limitations. The ML model enables random coefficients to follow any distribution and also does not have the iia property and can represent any substitution pattern $[17,27,28]$. While the ML model is the most advanced DCM available, its practical application is challenging for three reasons. First of all, model fitting is computationally expensive and not easily available in the commercial statistical software (Ststistical Analysis Software SAS). Second, the ML model is more appropriate for factors with continuous levels, since the coefficients will be estimated as distributions, but the continuous levels are difficult to design in DCEs [13,29]. Third, the coefficient of the demographic factors, willing to pay (WTP), and percent concordant and percent discordant cannot be estimated in the model, since the factors are no longer assumed to have the independence of the irrelevant alternatives (iia) property. Thus, while the two constraints (constant $\beta_{\mathrm{n}}$ and the iia property) that plague the CL and CLQ models are relaxed in the advanced ML model, the cost of relaxing these two limitations is large. The importance of this limitation depends on whether or not this information is necessary for achieving the goals of community engagement.

In this way, the performance of the $C L, C L Q$, and ML models need to be evaluated to determine the most suitable model for mining community engagement. The model comparison items are summarized in Figure 4. On the one hand, the model needs to meet the practical application of mining companies, enough useful information (coefficient of the demographic factors, distribution of the mining attribute, and willingness to pay), and acceptable application difficulty. On the other hand, the model result needs theoretical accuracy, which has a high likelihood ratio index (LRI) and percent concordant. The higher LRI, percent concordant and lower percent discordant indicate a more well-fitting and desirable model. The best DCM for mining community engagement may vary case by case, depending on different mining company considerations and local community needs.

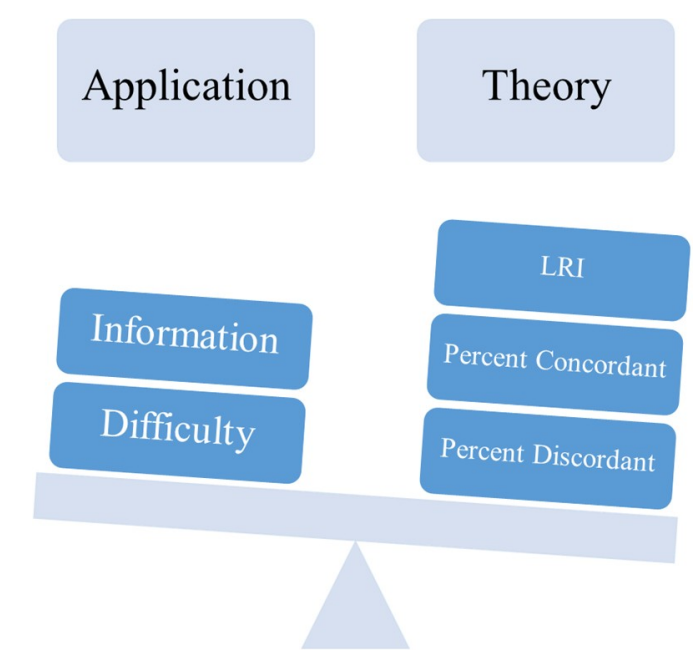

Figure 4. Model comparisons for mining community engagement. LRI, likelihood ratio index.

\section{A Case Study}

The primary goal of the developed framework is to understand the local mining community with a quantitative analysis method. In the first part of the developed framework, 16 mining attributes and six demographic factors were selected according to the literature review, taking the United States 
as the background. Social, economic, environmental, governance, and other categories are included in the 16 mining attributes. Meanwhile, the "age", "gender", "income", "education", "job field", and "number of children" were selected as the six demographic factors [28]. Afterward, the 16 mining attributes were validated using an online survey; which involves 100 respondents picked from twenty mining communities in the United States [20]. Respondents were requested to evaluate the significance in their decision, whether to support a new mine development in their vicinity, with each attribute, by choosing a number from 1 to 7 (" 1 " represents "not at all important" and " 7 " represents "extremely important"). The hypothesis is that, if the respondents rank an attribute greater than the median " 4 ", that attribute is considered relevant and valid. As a result, all 16 mining project attributes are identified as important factors based on the survey conducted. The six demographic factors were also investigated using the survey data. A demographic factor was regarded important when it was significantly (at the 0.05 significance level) correlated to at least one of the 16 mine attributes. Based on this criterion, the result of the statistical analysis suggests that four out of the six demographic factors are important (age, gender, income, and education) [21]. Finally, clarity and difficulty of the survey were examined employing a discrete choice experiment towards all 16 mining project attributes based on focus group study. The levels for clarity, effectiveness, and validity were adjusted according to the feedback from the focus group study. The final list is shown in Table 1 [20].

Table 1. The final list of mining project attribute and demographic factors [20].

\begin{tabular}{|c|c|c|}
\hline Economic & Social & Demographic Factors \\
\hline Job opportunities $[30,31]$ & Population increase $[30,32]$ & Age \\
\hline Income increase $[19,33]$ & Infrastructure improvement $[30,33]$ & Gender \\
\hline Increase in housing costs $[19,33]$ & Traffic increase $[32,34]$ & Household income \\
\hline Labor shortage for other businesses [33] & Crime increase $[32,34]$ & Education \\
\hline Environmental & Governance and others & \\
\hline Noise pollution $[33,34]$ & $\begin{array}{l}\text { Permit approval decision making } \\
\text { mechanism [35] }\end{array}$ & \\
\hline Water pollution $[19,36]$ & $\begin{array}{l}\text { Availability of independent and } \\
\text { transparent information on potential } \\
\text { impacts of mine }[30,35]\end{array}$ & \\
\hline Air pollution $[34,37]$ & Mine buffer [19] & \\
\hline Land pollution $[33,37]$ & Mine life [13] & \\
\hline
\end{tabular}

In the second part of the developed framework, the discrete choice experiment was designed with four attributes as a mixed style, a blocking scheme, a fractional factorial, and an experiment without interaction. The detail design and validation processes are shown in previous study [26]. A sample question for the discrete choice experiment has been shown in Table 2. The complete final survey is shown at link (http://web.mst.edu/ \{\}kabp3/jem2015supplement.htm). For the quality control, two quality control questions were inserted in the survey. Time control means that each survey will take about $15 \mathrm{~min}$. If the time used by a participant to take the survey is less than $7 \mathrm{~min}$, which is the minimum time to accomplish the survey in earnest, the data is regarded as invalid. The zip codes have been set in the survey to confirm the participants as a true local mining community by tracking respondents.

The survey was conducted in Salt Lake City, the capital of the U. S. state of Utah, which has a long history of mining. The world-renowned Bingham Canyon Mine is an open-pit mining operation extracting a large porphyry copper deposit southwest of Salt Lake City, Utah, in the Oquirrh Mountains. The mine is the largest man-made excavation in the world and is considered to have produced more copper than any other mine in history-more than 19 million tons. More than 1810 participates were recruited in this survey. Among them, 1062 participates responded and 822 accomplished all questions in the survey. Of the surveys, 44 were considered invalid because the quality control question was failed to be answered or the time of accomplishment was less than $7 \mathrm{~min}$. In additional, data from 
150 people were not included due demographic factors. As a result, 628 qualified participants are considered valid in this survey and the data will be processed further.

Table 2. A sample question for discrete choice experiment.

\begin{tabular}{|c|c|c|c|c|}
\hline \multicolumn{5}{|c|}{$\begin{array}{l}\text { A New Mine Will Be Opened Near Salt Lake. Carefully Consider Each of the Following Options. Suppose } \\
\text { All Other Unknown Conditions/Characteristics Are the Same, Which Option Would You Choose? }\end{array}$} \\
\hline & Job Opportunities & Water Pollution & $\begin{array}{l}\text { Permit Approval Decision } \\
\text { Making Mechanism }\end{array}$ & $\begin{array}{l}\text { Population } \\
\text { Increase }\end{array}$ \\
\hline Option A & $\begin{array}{l}600 \text { people } \\
\text { employed directly } \\
\text { by the mine }\end{array}$ & $\begin{array}{l}\text { Same as similar } \\
\text { mine in the area }\end{array}$ & $\begin{array}{l}\text { Final decision by } \\
\text { Government agency after } \\
\text { significant public input }\end{array}$ & $4 \%$ annually \\
\hline Option B & $\begin{array}{l}300 \text { people } \\
\text { employed directly } \\
\text { by the mine }\end{array}$ & $\begin{array}{l}\text { Same as similar } \\
\text { mine in the area }\end{array}$ & $\begin{array}{l}\text { Final decision by } \\
\text { Government agency after } \\
\text { negotiating with local } \\
\text { representatives }\end{array}$ & $2 \%$ annually \\
\hline Option C & $\begin{array}{c}900 \text { people } \\
\text { employed directly } \\
\text { by the mine }\end{array}$ & $\begin{array}{l}\text { Less than similar } \\
\text { mine in the area }\end{array}$ & $\begin{array}{l}\text { Final decision by } \\
\text { Government agency after } \\
\text { significant public input }\end{array}$ & $6 \%$ annually \\
\hline
\end{tabular}

In the third part of the developed framework, the authors conducted the conditional logit model (CL), the conditional logit model stratified by question (CLQ), and the mixed logit model (ML). The model results are shown in Table 3. Based on the model results, it can be concluded that the estimated values agreed with the discrete choice experimental data reasonably well. The goodness-of-fit of the CL model, CLQ model, and ML models are quite good, with an LRI (pseudo-R2) of 0.2687, 0.2696, and 0.3127. As a rule of thumb, well-fitting models have an LRI greater than 0.2 [25]. The goodness-of-fit of the ML model is slightly better than the CL and CLQ models. For the CL model, the percent concordant, the percent discordant, and the percent tied are $73.3 \%, 23.5 \%$, and $3.2 \%$, separately. The percent concordant of the CLQ model is $78.5 \%$, the percent discordant equals $18.7 .5 \%$, and the percent tied is $2.8 \%$. This information could not be estimated in the ML model. In general, higher percentages of concordant pairs and lower percentages of discordant and tied pairs indicate a more desirable model.

Table 3. Conditional logit model (CL), conditional logit model stratified by question (CLQ), and mixed logit model (ML) results comparison.

\begin{tabular}{ccccc}
\hline Model & LRI & Percent Concordant & Percent Discordant & Percent Tied \\
\hline CL model & 0.2687 & $73.3 \%$ & $23.5 \%$ & $3.2 \%$ \\
CLQ model & 0.2696 & $78.5 \%$ & $18.7 \%$ & $2.8 \%$ \\
ML model & 0.3127 & $\mathrm{X}$ & $\mathrm{X}$ & $\mathrm{X}$ \\
\hline
\end{tabular}

The primary goal of this study was to evaluate how these three typical DCMs respond to theoretical accuracy and practical application. From the case study, the CLQ results are better than the CL model results. The comparison between the CLQ and ML models needs to be discussed. First of all, the ML model is more suitable for factors with continuous levels, since the coefficients will be estimated as distributions. In this case study, only two out of 16 factors. These factors are "labor shortage for other business", estimated as normal distribution at a 10\% significant level and a "mine buffer" estimated as lognormal distribution at a $1 \%$ significant level. While other mining attributes could have continuous levels, such as "job opportunities", "income increase", and "mine life", their coefficient were not estimated as distributions in the ML model at any significant level. In additional, the coefficients of demographic factors could not be estimated in the ML model. The WTPs in the ML model are missing, since the integral does not have a closed form in general. The integral is approximated through simulation. The ML model lost the information of the percent concordant, which is important information to show the correct perdition percent. After balancing the advantages and disadvantages of each model, the case study reveals that the CLQ model appears to be suitable for mining community 
engagement. While the ML model is the most advanced DCM available, its practical application is challenging.

As shown by the CLQ model result (Table 4), the goal to use discrete choice theory for mining stakeholder analysis has been achieved by answering three important questions:

(1) What are the factors that affect an individual's decision and how do these affect the decision?

In Salt Lake City, there are 16 mining project characteristics that affect the communities' acceptance of a mining project, at $1 \%$ and $5 \%$ significance levels (Table 4 ). Of these, seven factors are positive (i.e., they positively correlate to the likelihood of individuals accepting a project) and the remaining are negative. These results are much more realistic than those obtained by soliciting such results from respondents independently. The discrete choice theory results are based on hypothetical choices that force respondents to make real trade-offs based on their perceived importance.

(2) What is the effect of demographics on individual preferences?

Age, household income, education and gender were found to significantly affect individual preferences at $5 \%$ and $10 \%$ significance levels. The result reveals that, in Salt Lake City, older males with higher household incomes and more education are more likely to prefer any particular mine option than younger females with lower household incomes and less education.

(3) What is the value of environmental and social impacts to individuals in the community?

There are nine negative mining project characteristics affecting the individual acceptance of a mining project at $1 \%$ and $5 \%$ significance levels. The results can be used to estimate the average Salt Lake City resident's WTPs (or value) for the undesirable effects of these factors. The ranking of predicted value of the negative effects, in additional income, is air pollution $(\$ 291 / \mathrm{month})>$ increase in housing costs $(\$ 280 /$ month $)>$ crime increase $(\$ 270 /$ month $)>$ noise pollution $(\$ 268 /$ month $)>$ water pollution $(\$ 55 /$ month $)>$ land pollution $(\$ 43 /$ month $)>$ traffic increase $(\$ 28 /$ month $)>$ labor shortage (\$18/month).

Table 4. The conditional logit stratified by questions (CLQ) Model results.

\begin{tabular}{|c|c|c|c|}
\hline Factors & CLQ-Coefficient & P-Value & WTP \$/Month \\
\hline \multicolumn{4}{|l|}{ Positive Factors } \\
\hline Job opportunities & 1.3886 & $<0.0001$ & 221 \\
\hline $\begin{array}{l}\text { Availability of independence and transparency } \\
\text { information on potential impacts of mine }\end{array}$ & 1.2606 & $<0.0001$ & 201 \\
\hline Income increase & 1.2541 & $<0.0001$ & 200 \\
\hline Mine buffer & 1.2141 & $<0.0001$ & 194 \\
\hline Infrastructure improvement & 1.1575 & $<0.0001$ & 185 \\
\hline Permit approval decision making mechanism & 0.2028 & $<0.0001$ & 32 \\
\hline Mine life & 0.1402 & 0.0023 & 22 \\
\hline \multicolumn{4}{|l|}{ Negative Factors } \\
\hline Air pollution & -1.8216 & $<0.0001$ & -291 \\
\hline Increase in housing costs & -1.7527 & $<0.0001$ & -280 \\
\hline Crime increase & -1.6939 & $<0.0001$ & -270 \\
\hline Noise pollution & -1.6794 & $<0.0001$ & -268 \\
\hline Water pollution & -0.3471 & $<0.0001$ & -55 \\
\hline Land pollution & -0.2707 & $<0.0001$ & -43 \\
\hline Population increase & -0.2570 & $<0.0001$ & -41 \\
\hline Traffic increase & -0.1742 & 0.0001 & -28 \\
\hline Labor shortage for other businesses & -0.1117 & 0.0157 & -18 \\
\hline \multicolumn{4}{|l|}{ Demographic factor } \\
\hline Age & 0.0028 & 0.0852 & \\
\hline Household income & 0.0021 & 0.0775 & \\
\hline Education & 0.0017 & 0.0905 & \\
\hline Gender & -0.0093 & 0.0928 & \\
\hline
\end{tabular}

WTP: willing to pay, is the maximum price at or below which a consumer will definitely buy one unit of a product. 


\section{Conclusions}

Successful application of discrete choice theory could improve mining sustainability by allowing mining companies to better understand what kind of mining project the community prefers and which demographic factors are crucial in dividing opinions. The application framework of discrete choice theory can support the whole community engagement process in three aspects. First of all, the framework could include all different kinds of mining attributes that influence the attitude, on mining projects, of a community, which identified those attributes from a literature review, expectations and the local community. Secondly, the framework allows different individuals to respond to mine development options, which could obtain information about how these demographic factors affect the local community perception of a mining project. Thirdly, the DCM estimates the quantitative coefficients of each mining attribute and demographic factor. The estimated parameters could explain how these factors affect the local community perception of a mining project quantitatively.

A case study is used to illustrate this developed framework. The research identified that 16 mining attributes are statistically significant in explaining individual preferences among our respondents, and the four demographic factors we investigated were shown to be statistically significant. In additional, the conditional logit (CL), strata conditional logit (CLQ) and mixed logit (ML) models were evaluated to investigate how these three typical DCMs respond to theoretical accuracy and practical application. After balancing the advantages and disadvantages of each model, the CLQ model is recommended as the most appropriate DCM for mining community engagement in this case study. The case study CLQ model result shows that the 16 mining attributes all affect the local mining community's preferences at a significant level, including seven positively and nine negatively correlated attributes. The influence of demographic factors on individual preferences is secondary to the mining attributes. This work finds that older males with higher income and education have a higher probability to prefer mining projects.

Our research has two main limitations that need to be clarified. First, this research provides a general framework for including discrete choice theory into improved community consultations in mining. In the case study, a discrete choice experiment (survey) was designed for a specific mining community (Salt Lake City, Utah, USA) to illustrate how to conduct such experiments. Thus, the resulting model applies to the target mining community only. However, the general framework and research approach can be used for other mining communities and even other fields. Secondly, the discrete choice modeling advocated in this framework treats all participants equally. Thus, this model can be applied to groups in which individuals have equal rights to support or reject a project. If other researchers want to employ this framework for multi-stakeholders (employees, customers, affected communities and the general public) at the same time, a possible approach is to establish one discrete choice model (DCM) for each group, and combine the results.

Future research could extend the observations on the classification of important factors and discrete choice modeling to other mining contexts. Currently, most mining projects are moving to developing countries, such as China. However, the benefits and costs to local mining communities have not been studied thoroughly. The discrete choice model result can be used to get a better understanding of the determinants of community acceptance in those contexts. The selection and classification of mining characteristics and demographic factors may vary between different communities and countries. Thus, the author suggests that the whole methodology of this study should be applied to select the important factors for a given target mining communities' acceptance of mining projects, to design the discrete choice experiments, and to conduct discrete choice modeling with the data. Then, the discrete choice model result would help the mining community to plan, design, process, and manage mining projects better.

Author Contributions: Conceptualization, S.Q.; Methodology, S.Q. and H.J.; Formal Analysis, S.Q. and W.Y.; Writing-Original Draft Preparation, S.Q. and L.W.; Writing-Review \& Editing, L.W. and K.A.-O. 
Funding: This work was financially supported by Venture\& Innovation Support Program for Chongqing Overseas Returnees (Grant No.cx2018114), Key Laboratory of Hydraulic and Waterway Engineering of the Ministry of Education, Chongqing Jiaotong University (Grant No. SLK2017A04), the National Key Lab Research Program of China (Grant No.2016YFC0402103), the Science and Technology Research Program of Chongqing Municipal Education Commission (Grant No. KJ1600541), the Basic Science and Frontier Technology Research Program of Chongqing Science and Technology Commission(Grant No. cstc2016jcyjA0428) the Science and Technology Research Program of Chongqing Municipal Education Commission (Grant No. KJ1705140).

Conflicts of Interest: The authors declare no conflict of interest.

\section{References}

1. Kuhn, A. In Indonesia, Anger Against Mining Giant Grows. Available online: https://www.npr.org/2011/11/ 16/142346962/in-indonesia-anger-against-mining-giant-grows (accessed on 22 November 2018).

2. O'Faircheallaigh, C. Government and Business in Volatile Times. In Corporate Social Responsibility; Acker, E.V., Curran, G., Eds.; Pearson: Sydney, Australia, 2013.

3. Owen, J.R.; Kemp, D. Social licence and mining: A critical perspective. Resour. Policy 2013, 38, $29-35$. [CrossRef]

4. Pactwaa, K.; Woźniaka, J.; Strempskib, A. Sustainable mining-Challenge of Polish mines. Resour. Policy 2018. [CrossRef]

5. Curran, G. Social licence, corporate social responsibility and coal seam gas: framing the new political dynamics of contestation. Energy Policy 2017, 101, 427-435. [CrossRef]

6. Woźniak, J. The Role and Implementation of the Concept of Social Responsibility in the Functioning of Mining and Energy Industry; Geoengineering, Mining and Geology Wrocław University of Science and Technology: Wrocław, Poland, 2019. (In Polish)

7. Mason, R.; Mitroff, I. Challenging Strategic Planning Assumptions; John Wiley \& Sons: New York, NY, USA, 1981.

8. Crosby, B. Stakeholder Analysis: A Vital Tool for Strategic Managers; USAID: Washington, DC, USA, 1992.

9. Walt, G. Can Interest Groups Influence Government Policy? Health Policy: An Introduction to Process and Power; Zed Publications: London, UK, 1994.

10. Que, S.; Wang, L.; Awuah-Offei, K.; Chen, Y.; Yang, W. The Status of the Local Community in Mining Sustainable Development beyond the Triple Bottom Line. Sustainability 2018, 10, 1749. [CrossRef]

11. McFadden, D. Conditional Logit Analysis of Qualitative Choice Behavior; Frontiers in Econometrics: New York, NY, USA, 1974.

12. Walekhwa, P.N.; Mugisha, J.; Drake, L. Biogas energy from family-sized digesters in Uganda: Critical factors and policy implications. Energy Policy 2009, 37, 2754-2762. [CrossRef]

13. Willis, K.; Scarpa, R.; Gilroy, R.; Hamza, N. Renewable energy adoption in an ageing population: Heterogeneity in preferences for micro-generation technology adoption. Energy Policy 2011, 39, 6021-6029. [CrossRef]

14. Winslott Hiselius, L. Using choice experiments to assess people's preferences for railway transports of hazardous materials. Risk Anal. 2005, 25, 1199-1214. [CrossRef]

15. Dimitropoulos, A.; Kontoleon, A. Assessing the determinants of local acceptability of wind-farm investment: A choice experiment in the Greek Aegean Islands. Energy Policy 2009, 37, 1842-1854. [CrossRef]

16. StatWizards LLC. Discrete Choice Models; StatWizards LLC: Coronado, CA, USA, 2016.

17. Que, S. Describing Local Community Acceptance with Discrete Choice Theory for Enhanced Community Engagement. Doctoral Dissertations, Missouri University of Science and Technology, Rolla, MO, USA, 2015.

18. Ivanova, G.; Rolfe, J.; Lockie, S.; Timmer, V. Assessing social and economic impacts associated with changes in the coal mining industry in the Bowen Basin, Queensland, Australia. Manag. Environ. Qual. An Int. J. 2007, 18, 211-228. [CrossRef]

19. Ivanova, G.; Rolfe, J. Assessing development options in mining communities using stated preference techniques. Resour. Policy 2011, 36, 255-264. [CrossRef]

20. Que, S.; Awuah-Offei, K.; Wang, L.; Samaranayake, V.A.; Weidner, N.; Yuan, S. Individual preferences for mineral resource development:Perspectives from an urban population in the United States. J. Clean. Prod. 2018, 189, 30-39. [CrossRef] 
21. Que, S.; Awuah-Offei, K.; Samaranayake, V.A. Classifying critical factors that influence community acceptance of mining projects for discrete choice experiments in the United States. J. Clean. Prod. 2015, 87, 489-500. [CrossRef]

22. Ryan, M.; Gerard, K. Using discrete choice experiments to value health care: Current practice and future prospects. Appl. Heal. Econ. Policy Anal. 2003, 2, 55-64.

23. Train, K. Discrete Choice Methods with Simulation; Cambridge University: Cambridge, UK, 2002.

24. Caussade, S.; Ortúzar, J.D.D.; Rizzi, L.I.; Hensher, D.A. Assessing the influence of design dimensions on stated choice experiment estimates. Transp. Res. Part B Methodol. 2005, 39, 621-640. [CrossRef]

25. Hoyos, D. The State of the Art of Environmental Valuation with Discrete Choice Experiments. Ecol. Econ. 2010, 69, 1595-1603. [CrossRef]

26. Que, S.; Awuah-Offei, K.; Weidner, N.; Wang, Y. Discrete choice experiment validation: A resource project case study. J. Choice Model. 2017, 22, 39-50. [CrossRef]

27. Mcfadden, D.; Train, K. Mixed MNL models for discrete response. J. Appl. Econom. 2000, 15, 447-470. [CrossRef]

28. Que, S.; Awuah-Offei, K. Framework for mining community consultation based on discrete choice theory. Int. J. Min. Miner. Eng. 2014, 5, 59-74. [CrossRef]

29. Revelt, D.; Train, K. Mixed Logit with Repeated Choices: Households' Choices of Appliance Efficiency Level. Rev. Econ. Stat. 1998, 80, 647-657. [CrossRef]

30. ICMM. Mining's Contribution to Sustainable Development-An Overview Mining's Contribution to Sustainable Development; ICMM: London, UK, 2012.

31. IFC. Good Practice note: Addressing Grievances from Project-Affected Communities; IFC: Washington DC, USA, 2009.

32. Lockie, S.; Franettovich, M.; Petkova-Timmer, V.; Rolfe, J.; Ivanova, G. Coal mining and the resource community cycle: A longitudinal assessment of the social impacts of the Coppabella coal mine. Environ. Impact Assess. Rev. 2009, 29, 330-339. [CrossRef]

33. Petkova, V.; Lockie, S.; Rolfe, J.; Ivanova, G. Mining developments and social impacts on communities: Bowen Basin case studies. Rural Soc. 2009, 19, 211-228. [CrossRef]

34. ICMM; ICRC; IFC; IPIECA. Voluntary Principles on Security and Human Rights: Implementation Guidance Tools; ICMM: London, UK; ICRC: Geneva, Switzerland; IFC: Washington DC, USA; IPIECA: London, UK, 2011.

35. Muradian, R.; Martinez-Alier, J.; Correa, H. International capital versus local population: The environmental conflict of the Tambogrande mining project, Peru. Soc. Nat. Resour. 2003, 16, 775-792. [CrossRef]

36. ICMM. Good Practice Guide: Indigenous Peoples and Mining; ICMM: London, UK, 2010.

37. Dudka, S.; Adriano, D.C. Environmental Impacts of Metal Ore Mining and Processing: A Review. J. Environ. Qual. 1997, 26, 590. [CrossRef]

(C) 2019 by the authors. Licensee MDPI, Basel, Switzerland. This article is an open access article distributed under the terms and conditions of the Creative Commons Attribution (CC BY) license (http://creativecommons.org/licenses/by/4.0/). 